\title{
Evaluation of Mandibular Ramus Area According to Age and Gender Using Computed Tomography
}

\author{
Alaa S Mahdi (BDS,MSc) ${ }^{1}$
}

Abstract

Background:Ramus area is an important landmark of the mandiblular bone which influenced by gender, age and dental status.

Objective: To evaluated the changes occur in this part of the mandible (ramus height ,ramus depth and bone density)to investigate the effect of age and gender on mandibular ramus shape and density using computed tomography.

Patients and Methods: A total 100 patients CT scan (prospective study)panoramic view were evaluated and divided into 4 groups each group includes 25 patients $\left(1^{\text {st }}\right.$ male group 50 years, $2^{\text {nd }}$ male $<50$ years, $3^{\text {rd }}$ female group50 years and 4 th female group <50years.) Ramus height ,depth and bone density in this part were measured.All the samples were class I skeletal pattern and good dental status, All the sample was with semi- full set of teeth to avoid the effect of dental status on the results of this study as minimum as possible.

Results: The effect of age was obvious on ramus height ,Bone Density was significant and highly significant respectively, while the depth non-significant at compare the age only not regarded to gender(50sample young less than 50years and the same older than 50years) .The effect of age with gender were compare female and male above 50y showed ramus height ,Bone Density were significant and highly significant(p-value $=0.01$ and $p=0.00$ ) for bone density, while the ramus depth non-significant. Females with age had decreased in bone density and increased in ramus height rather than male with same age group(hormonal effect).Males groups comparison ramus height $\mathrm{p}=0.01$ significant ,Bone Density $\mathrm{p}=0.00 \mathrm{H}$. Significant. Ramus depth was non-significant(males groups) that explain the other factors like( smocking ,nutrition ,habit ) affected this part in same pattern that hormonal effect on women.

Conclusion: This study explained the effect of age and gender on the ramus area the ramus height ,bone density play important role in significances determination rather than ramus depth .This landmark (ramus area)could be implicating in forensic dentistry as an aid in gender determination.

Keywords:Ramus Height(RH),Ramus Depth(RD),Bone Density(BD),Computed Tomography(CT).

Corresponding Author: Alaa.salah.8.42019@gmail.com

Received: $14^{\text {th }}$ November 2019

Accepted: $15^{\text {th }}$ December 2019

DOI:https://doi.org/10.26505/DJM.18025021114

${ }^{1}$ Collage of Dentistry - University of Baghdad- Baghdad -Iraq 


\section{Introduction}

The mandible is one of the body bones that affected by age processing and change in metabolic activity and hormonal disturbance like the other bones. The mandible bone divided into many areas in order to study of many analysis lines and angles (linear and angular measurements) examples on these areas gonial and antigonial area ramus condoyle area [1].

Ramus area that part occupied by ramus bone and have many anatomical landmarks that can be explain the age and gender effect on this part of mandible bone .examples ramus length and ramus notch [1] [2].

In forensic dentistry the mandible regard good indicator for distinguishing of gender and age determination from either teeth or bone morphology changes (gonial angle, mandible cortex index, panoramic index) also this bone affected by osteoporosis (especially in post-menopausal females). The height and depth of ramus could be change according to the age and effectiveness of hormonal disturbance and dental status [3].

Ramus height and notch also affected by skeletal pattern (class I, II and III craniofacial) so this part of mandibular bone should pay a lot of attention from the dentist and the radiologist specially [4].

\section{Patients and Methods}

In this study100CT scan for patient attained Baghdad Hospital in Baghdad city for different purposes were examined. Any patient complain from bone disease, TMJ disorder, excessive surgery in mandible ,thyroid abnormalities were excluded from the study in addition to edentulous or semi edentulous patient. The sample divided in to 4 groups :

1-25male with age range (20-30)years

2-25male above 50 years

3-25female with age range (20-30)years

4-25 female above 50years

Measurement of ramus height was done by drawing two lines ,the $1^{\text {st }}$ line was perpendicular to the ramus tangent line at the level of the most lateral image of the condoyle and the other line was perpendicular to the tangent line (All measurements were in $\mathrm{mm}$ ).The depth was measured by measuring the distance along perpendicular line from the deepest point of the notch concavity to the tangent line of the ramus [1].The density of bone (HU) was measured by applying the density icon on the area around the centre of ramus depth in Hounsfield unit(HU). The measurement done on panoramic view of computed tomography .In this study mean of the right and left side were taken as one score for each sample.

\section{Statistical analysis}

Statistical analysis was done by using SPSS software the version was 17.00.mean value and $p$ value and t-test were calculated for categorical variable for effect and significance.

\section{Results}

Regardless the gender ,comparison between (20-30)years and above 50 years subjects as explained by Table (1) the mean of RH elevated from 36.99 to 37.46 between 2 groups(t-test -3.59,p-value 0.001) significant. Ramus depth depressed between groups from 
1.064 to 0.77 but it's not significant ( p. value o.13 t-test $=2.536$ ) Bone density depressed from 1908.52 to 1226.98 from young to old one( t-test $=11.65$ ) it was highly significant( $\mathrm{p}$-value $=0.00)$ that was.

The effect of gender on variables (regardless the age).as shown in Table (2) explain the mean of ramus height( $\mathrm{RH})$ difference between male and female elevated from 34.03 to 37.42 and(t-test -2.927$)$ this variable was significant ( $p$-value $=0.04)$ R.D depressed from 0.9 to 0.8 between males and females so the ( t-test 1.059) so it's not significant (p-value 0.292).B.D mean depressed from 1681.84 to 1453 between males and females( t-test 2.612 p-value 0.10 ) significant. In Table (3) only the bone density BD show significant differences between male and female below50y ( $\mathrm{p}_{-}$value 0.11 and 0.12 ) even the mean value decreased from 2033.23 to 1783.72 other values were not significant. When a comparison done between males and females $>50$ (old age) $\mathrm{RH}$ and BD showed highly significant differences between males and females $\mathrm{RH}$ (p-value was 0.01 and 0.00 ) for $\mathrm{BD}$.while the RD was non significant. According to Table (5) the compares between males (above and below 50y) showed that only the bone density was highly significant ( $p$-value 0.00and the t-test 7.55) other variable showed no significant.

The Table (6) show compassion between females above and below 50y showed the mean value of RH elevated between 36.12 to 37.73 from $<50 y$ to $>50 y$ (t-test was -4.05 andp-value 0.00 ) highly significant.

$\mathrm{RD}$ the mean value depressed from 1.04 to 0.66 from $<50 \mathrm{y}$ to $>50 \mathrm{y}$ t-test was $2.32 \mathrm{p}$ value 0.1 significant .Bone density the mean depressed from 1783.72 to 1123.6 from $<50 y$ to $>50 y($ t-test was 11.8 andp-value 0.00 ) highly significant.

Table (1): Distribution of test and control subjects according to age and parity

\begin{tabular}{|c||c||c||c||c||c||c||}
\hline & Age & $\mathrm{N}$ & mean & T-test & P value & SD \\
\hline \hline RH & $<50$ & 50 & 36.99 & -3.59 & 0.001 & 1.6 \\
\hline \hline & $>50$ & 50 & 37.46 & -3.59 & 0.001 & 1.4 \\
\hline \hline RD & $<50$ & 50 & 1.064 & 2.536 & 0.13 & 0.9 \\
\hline \hline & $>50$ & 50 & 0.77 & 2.536 & 0.13 & 0.68 \\
\hline \hline BD & $<50$ & 50 & 1908.52 & 11.65 & 0.00 & 17 \\
\hline \hline & $>50$ & 50 & 1226.98 & 11.65 & 0.00 & 11 \\
\hline
\end{tabular}

Table (2): Statistical evaluation of variable according to gender

\begin{tabular}{|c|c|c|c|c|c|c|}
\hline & Gender & $\mathrm{n}$ & mean & T test & p-value & SD \\
\hline \multirow[t]{2}{*}{$\mathrm{RH}$} & Male & 50 & 34.03 & -2.927 & 0.04 & 1.4 \\
\hline & Female & 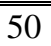 & 37.42 & -2.927 & 0.04 & 1.38 \\
\hline \multirow[t]{2}{*}{$\mathrm{RD}$} & "Male & 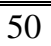 & 0.980 & 1.059 & 0.292 & 0.2 \\
\hline & Female & 50 & 0.854 & 1.059 & 0.292 & 0.26 \\
\hline \multirow[t]{2}{*}{$\mathrm{BD}$} & Male & 50 & 1681.84 & 2.612 & 0.1 & 11 \\
\hline & Female & 50 & 1453 & 2.612 & 0.1 & 11.8 \\
\hline
\end{tabular}


Table (3): Compaire of variables between males and females in young samples (20-30.)years

\begin{tabular}{||c||c||c||c||c||c||c||}
\hline \hline Age & Variable & gender & $\mathrm{N}$ & Mean & T_test & P_value \\
\hline \hline$<50$ & RH & male & 25 & 36.86 & -1.25 & 0.215 \\
\hline \hline & & Female & 25 & 37.12 & 1.25 & 0.215 \\
\hline \hline & RD & Male & 25 & 1.084 & 0.22 & 0.827 \\
\hline \hline & & Female & 25 & 1.044 & 0.22 & 0.827 \\
\hline \hline & BD & Male & 25 & 2033.23 & 2.64 & 0.11 \\
\hline
\end{tabular}

Table (4): Compare males and females variables in an old ages (above50years)

\begin{tabular}{|c|c|c|c|c|c|c|}
\hline Age & variable & gender & $\mathrm{n}$ & mean & t-test & $P_{P \_ \text {value }}$ \\
\hline$>50$ & RH & Male & 25 & 37.204 & -3.58 & 0.01 \\
\hline & & female & 25 & 34.82 & $\begin{array}{l}-3.58 \\
\end{array}$ & 0.01 \\
\hline & RD & Male & 25 & 0.876 & 1.466 & 0.144 \\
\hline & & female & 25 & 0.664 & 1.466 & 0.144 \\
\hline & BD & Male & 25 & 1330.36 & 3.87 & 0.00 \\
\hline & & female & 25 & 1123.6 & 3.87 & 0.00 \\
\hline
\end{tabular}

Table (5): Compare the variables between same gender (20-30)years and above 50 years in males

\begin{tabular}{|c||c||c||c||c||c|c||}
\hline gender & Variables & Age & n & mean & t-test & p-value \\
\hline \hline Male & RH & $<50$ & 25 & 36.86 & -1.66 & 0.102 \\
\hline \hline & & $>50$ & 25 & 37.24 & -1.66 & 0.102 \\
\hline \hline & RD & $<50$ & 25 & 1.08 & 1.26 & 0.21 \\
\hline \hline & & $>50$ & 25 & 0.87 & 1.26 & 0.21 \\
\hline \hline & BD & $<50$ & 25 & 2033.3 & 7.55 & 0.00 \\
\hline \hline
\end{tabular}

Table (6): Compare the variables between same gender (20-30)years and above 50 years in females

\begin{tabular}{||c||c||c||c||c|c|c||}
\hline Gender & Variables & Age & $\mathrm{n}$ & Mean & t-test & p-value \\
\hline \hline female & RH & $<50$ & 25 & 36.124 & -4.05 & 0.00 \\
\hline \hline & & $>50$ & 25 & 37.73 & -4.05 & 0.00 \\
\hline \hline & RD & $<50$ & 25 & 1.04 & 2.32 & 0.1 \\
\hline \hline & & $>50$ & 25 & 0.66 & 2.32 & 0.1 \\
\hline \hline & BD & $<50$ & 25 & 1783.72 & 11.8 & 0.00 \\
\hline \hline & & $>50$ & 25 & 1123.6 & 11.8 & 0.00 \\
\hline
\end{tabular}

\section{Discussion}

Statistical analysis was carried out by using t-test ,p-value ,mean value comparison,correlation of age and gender on ramus of the mandible. In comparison the age effect only (regardless the gender) showed RH was p-value 0.001 significant and $\mathrm{BD}$ was H.S p-value $=0.00$ while that agree with[6][1].RD non-significant 
Compare male above 50 years. And female above 50 years according to Table (2) RH and BD showed highly significant differences between male and female above 50y.p-value 0.04 and 0.00 t-test =2.927and2.621 for RH and BD correspond that mean the gender above 50years had direct effect on the height and bone density in this area of mandible that agree with Preston B el-al2002 [8].The comparison the female and male with 20-30years showed that only the bone density was significant differences in this area in same comparison female and male but above 50years. BD and RH was H.S p-value $=0.00$ t-test $=-3.58, \mathrm{RH}$ in old age female effect more than in male that agree with [5].

Hormonal disturbance osteoporosis , osteopenia, repeated pregnancy, breast feeding had direct effect on the shape and density of bone that agree with [7][8].comparison of females group above and below 50y RH and BD were H.S p-value $=0.00$ and $\mathrm{RD}$ was $\mathrm{p}$-value $=0.1$ significant that showed the effect of postmenopausal in females on this part of mandible that agree with Larhen et al.[9][10].

While comparison of males groups above and below 50 years. RH p-value $=0.01$ significant andBD was H.S p-value= 0.00andthe depth was no significant, that explained by other factors such as smoking ,nutritional factor habitats affected on the this area of mandible [11].many other factors may influence the bone density such body weight and vitamins especially D3, calcium,play important role in bone density [4].

\section{Conclusions}

Ramus area as a part of mandible had its own changes effect by age and gender and could be used in evaluation of age and gender in forensic dentistry.

\section{References}

[1]Abu-taleb N 1E Beshaawy D.Mandibular ramus and gonial angle measurement as predictors of sex and age in an Egyption population sample: Adigital panoramic study .JForensic 2015;6:1-7.

[2]Q.F.Xie and A.Ainamo, Association of mandibular angle size with cortical thickness and residual ridge height of the edentulous mandibule ,Zhonghua Kou Qiang Yi Xue ZaZhi 2014;vol.39,no.5,pp.390-394.

[3]Chole R, Patil R,CHOLE S,Gondivkar S Gadbil A Association of mandibular anatomy with age, gender and dental status :A R adiographic study.ISRN Radiology .2013;14.

[4]S.Ghosh,M.Vengal,K.M.Pai,andK.abhishe $\mathrm{k}$, Remodelling of the Ramus reigon in human mandibule :apanoramic radiographic cross-section study,,Medicina Oral Patologia Oraly Cirugia .2017; vol.15,no.5,pp.e802e807.

[5]K.Mattila ,M.Altonen ,and K.Haavikko, ,Determination of the Ramus Hieght and depth from the orthopantomogram ,linear Orthodontist.2007;vol.47,no.2 ,pp107-110.

[6]B.Baydas,I.Yavas,L.Taubman, andA.Gavis $\mathrm{h}, \mathrm{An}$ investigation of maxillary and mandibule morphology in different age 
groups,,Australian

Orthodontic

Journal2007;vol.20,no.1,pp.11-18.

[7]S. Ghosh ,M.Vengal,K.M.Pai,and K.Abhishek ,Remodeling of the Ramus height region in human mandible :panoramic radiographic cross-section study,,Oral Surgery,Oralpathology.2010;vol.15,no.5pp.e 802-e804.

[8]Preston B,Al-SehbaibanyF,Salem O.The morphology of the mandibular Ramus notch and facial symmetry. J Clin Pediator Dent. 2002;26:155-60.

[9]Larhein TA,SvanaesDB.,,Mandibular linear dimensions and angles .2009; vol.11,pp11-10.

[10]Ali LM ,Yamada K. Mandibular antigonial and ramus notch depth and condylar bone change. J Oral Rehabil.2009;32:1-6.

[11]Enlow DH,Bianco HJ,Ekliund S.The remodelling of mandibule .J

Prosthet.2001;39:685-93. 